\title{
GMR
}

\section{Atherosclerosis: analysis of the eNOS (T786C) gene polymorphism}

\author{
A.M. Barbosa ${ }^{1,2}$, K.S.F. Silva ${ }^{1}$, M.H. Lagares ${ }^{1,2}$, D.A. Rodrigues ${ }^{1,2}$, \\ I.R. da Costa ${ }^{1,2}$, M.P. Morais ${ }^{1,2}$, J.V.M. Martins ${ }^{1,2}$, R.S. Mascarenhas ${ }^{1}$, \\ F.L. Campedelli ${ }^{1,2}$ and K.K.V.O. Moura ${ }^{1,2}$ \\ ${ }^{1}$ Departamento de Biologia, Núcleo de Pesquisas Replicon, \\ Pontifícia Universidade Católica de Goiás, Goiânia, GO, Brasil \\ ${ }^{2}$ Departamento de Biomedicina, Pontifícia Universidade Católica de Goiás, \\ Goiânia, GO, Brasil \\ Corresponding author: K.S.F. e Silva \\ E-mail: smallbinho@hotmail.com \\ Genet. Mol. Res. 16 (3): gmr16039708 \\ Received April 24, 2017 \\ Accepted August 17, 2017 \\ Published September 21, 2017 \\ DOI http://dx.doi.org/10.4238/gmr16039708 \\ Copyright $(92017$ The Authors. This is an open-access article distributed under the terms of \\ the Creative Commons Attribution ShareAlike (CC BY-SA) 4.0 License.
}

\begin{abstract}
The coronary arteriosclerotic disease is the most common cardiovascular disease. Atherosclerosis affects large- and medium-sized arteries leading to severe thrombosis or artery stenosis that could evolve to myocardial infarction, ischemic stroke, ischemic injury of kidneys and intestines, and several other life-threatening clinical manifestations. Nitric oxide has been shown to be a promising therapeutic agent against cardiovascular diseases. The eNOS gene assumes several important functions, including regulation of vascular tone and regional blood flow, the suppression of vascular smooth muscle cell proliferation, and modulation of leukocyte-endothelium interactions. The $T 786 \mathrm{C}$ polymorphism is an important point mutation, where thymine is changed to cytosine. $T 786 \mathrm{C}$ significantly reduces the activity of the eNOS promoter gene. Two hundred and ninety-seven peripheral blood samples were collected from patients with the previous diagnosis of atherosclerotic disease based on clinical examination and
\end{abstract}

Genetics and Molecular Research 16 (3): gmr16039708 
confirmed by imaging methods. Results were compared using the chisquare test and the G-test. In the present study, the TC genotype was more frequent in both case and control groups with no statistically significant difference. Comparing the relation TC/TT and CC genotypes in the case and control groups, there was no statistically significant difference. No significant difference was found when genotypes were analyzed regarding gender and smoking. Our results suggest a strong tendency of the $\mathrm{T}$ allele, in single or double dose, to be associated with atherosclerosis that was not confirmed by the scientific data.

Key words: Atherosclerotic lesion; eNOS; Polymorphism; Genotype

\section{INTRODUCTION}

Coronary arteriosclerotic disease (CAD) is the most common cardiovascular disease. $\mathrm{CAD}$ is a multifactorial disorder with complex etiology and influenced by genetic and environmental components (Nanni et al., 2006).

The increased incidence of cardiovascular diseases is likely the result of a high prevalence of non-traditional risk factors such as inflammation, oxidative stress, infectious agents, and traditional risk factors such as hypertension, dyslipidemia (Balagopal et al., 2011), smoking, and increased glycemia that contribute to the disorder chronicity or super stimulation of the vascular endothelium. These factors together, synergistically stimulate the production of inflammatory cytokines, lipid peroxidation, and oxidative stress, which increase the adhesive surface of the endothelium and decrease the production of relaxing factors and anticoagulants derived from endothelium (Félétou and Vanhoutte, 2006).

Atherosclerosis affects large- and medium-sized arteries leading to severe thrombosis or artery stenosis that could evolve to myocardial infarction, ischemic stroke, ischemic injury of kidneys and intestines, and several other life-threatening clinical manifestations.

Before it becomes clinically evident, the atherosclerotic process progresses silently for years. The progression of atherosclerosis is characterized by the development of plaques within the arteries, leading to a reduced supply of oxygen-rich blood to the organs and other parts of the body (Puddu et al., 1995). The evolution of CAD, from an initial lesion to a plaque rupture, is due to many cellular and molecular events that lead to an inflammatory stage (Robert, 2005). Recent advances have established a crucial role for inflammation in all phases of atherosclerosis, including initiation, progression, and complicated advanced injury since inflammation has emerged as an important driving force in the initiation and progression of atherosclerotic lesion formation (Libby, 2013).

Common predisposing conditions for atherosclerosis such as hypercholesterolemia, hypertension, diabetes, and smoking are associated with endothelial dysfunction, leading to a proinflammatory and prothrombotic endothelial phenotype (Konsola et al., 2016). Advanced understanding of the pathobiology of atherosclerosis suggests that such alterations of endothelial function may play a key role in the development and progression of atherosclerosis and its clinical complications (Landmesser et al., 2004). Endothelial dysfunction is faced as an early marker for the initiation and progression of atherosclerosis and a predictor of future cardiovascular events (Giannotti and Landmesser, 2007). Moreover, atherosclerosis is associated with a great change in the endothelial phenotype, and the assessment of endothelium-

Genetics and Molecular Research 16 (3): gmr16039708 
dependent vasodilator function of the peripheral arteries has emerged as an accessible indicator of endothelial health (Charakida et al., 2010).

Endothelial dysfunction is an early and important event that initiates atherogenesis, and this is mainly mediated through the impaired regulation of endothelial nitric oxide synthase (eNOS) with a decrease in vasoprotective nitric oxide (NO) and increased production of reactive oxygen species that promote vascular injury (Gorenne et al., 2006).

Cardiovascular diseases such as hypertension, atherosclerosis, and diabetes mellitus are associated with decreased NO bioactivity due to a reduced NO production by eNOS or an increase in NO inactivation after the reaction with superoxide ( $\mathrm{Li}$ and Förstermann, 2009; Konsola et al., 2016). eNOS and NO derivatives have several important functions, including regulation of vascular tone and regional blood flow, suppression of vascular smooth muscle cell proliferation, and modulation of leukocyte-endothelium interactions (Davignon and Ganz, 2004). NO has been shown to be a promising therapeutic agent. It is synthesized from L-arginine by NOS, which has three isoforms: neuronal, inducible, and eNOS. eNOS is regulated by estrogen and can be altered by drugs, including cigarettes, and by several diseases, such as hypercholesterolemia, diabetes, and hypertension (Li et al., 2002). eNOS is a potent oxidant produced by endothelial cells and macrophages that exert protective and atherogenic effects. The NO produced by eNOS has vasodilator functions and besides being potentially atheroprotective (Li and Förstermann, 2009).

Genetic polymorphisms of eNOS were shown to have a significant effect on NO levels in plasma lipids and were associated with diabetes mellitus (Monti et al., 2003), cardiac insufficiency (McNamara et al., 2003), coronary spasm (Lüscher and Noll, 1999), atherosclerosis (Paradossi et al., 2004), myocardial infarction, hypertension (Yoshimura et al., 2003), and intra-stent coronary restenosis (Gomma et al., 2002).

Due to pleiotropic effects of NO, several studies have investigated the link between eNOS polymorphisms and the development of coronary events. Among the many polymorphisms reported regarding the eNOS gene, two polymorphisms, namely Glu298Asp (G:T) located within exon 7 and T-786C within the promoter, have received much interest in the possible association between such polymorphisms and CAD (Zeng et al., 2017), and the latter has been more intensely investigated (Miyamoto et al., 2000; Nakayama et al., 2000). It involves a cytosine (C) substitution of the thymine nucleotide (T) at the 786 locus of the eNOS gene and is associated with increased susceptibility to coronary vasospasm in homozygotes $(\mathrm{C} / \mathrm{C})$ and heterozygotes $(\mathrm{T} / \mathrm{C})$, that is individuals expressing the mutant allele $(\mathrm{C}$ allele) (Lüscher and Noll, 1999; Nakayama et al., 1999).

Health care professionals should not only treat clinically atherosclerotic cardiovascular disease manifestations but also identify targets for prevention and early treatment in apparently healthy individuals. Both tasks require an understanding of the pathogenesis of atherosclerosis. In the present study, we analyzed the T786C polymorphism of the eNOS gene in a group of individuals diagnosed with atherosclerosis and in a control group.

\section{MATERIAL AND METHODS}

The research was approved by the National Ethics Committee in Research/ National Information System on Ethics in Research Involving Human Beings CEP/PUC Goiás (Number: 35321614.3.0000.0037). All patients signed the informed consent term and agreed to participate in the research. Inclusion criteria were patients over 38 years of age, diagnosed

Genetics and Molecular Research 16 (3): gmr16039708 
with atherosclerosis under medical treatment and/or submitted to interventional vascular procedures and who agree to respond to the questionnaire and signed the free and informed consent form. Exclusion criteria were patients under 38 years of age and who did not agree to participate in the study. For the control group, inclusion criteria were age over 38 years who did not present a diagnosis of atherosclerotic disease based on clinical criteria and/or imaging tests. Exclusion criteria were patients under 38 years of age who did not agree to participate in the study.

The SNP ID numbers and sequence information used in the present study are available publicly (http://www.ncbi.nlm.nih.gov/SNP/). We selected for the present study the SNP T-786C (rs 2070744).

We collected peripheral blood samples from 197 patients with the previous diagnosis of atherosclerotic disease confirmed by image methods. We also collected 100 blood samples from patients, based on clinical manifestations and noninvasive imaging methods, to compose the control group. The samples were from patients of the Cardiology and Peripheral Vascular Surgery Department of the Angiogyn Clinic in the city of Goiânia in the period from October 2014 to February 2015. The peripheral blood samples were collected and subjected to molecular tests to detect the eNOS (T786C) gene polymorphism.

Regarding smoking, the case and control groups were arranged into three groups: current smokers, non-smokers, and ex-smokers. According to the guidelines of the Brazilian Medical Association in 2013, a smoker refers to a person who makes regular use of at least one of the products of tobacco regardless the period the product is consumed; ex-smoker refers to the individuals who in the past have made use of tobacco products, do not smoke currently, and has stopped smoking for a period greater than or equal to 15 years.

DNA extraction was performed according to Kaswi ${ }^{\circledR}$ (Genomic DNA Purification Kit) instructions. After extraction, the samples were quantified in the NanoVue ${ }^{\mathrm{TM}}$ Plus Spectrophotometer (GE, Cambridge, UK) according to the manufacturer's instructions, with relevance only to samples whose quantification results concerning DNA concentration were higher than $5 \mathrm{ng} / \mu \mathrm{L}$. The $260 / 280 \mathrm{~nm}$ ratio was used to estimate the purity of the DNA samples. DNA was stored at $-20^{\circ} \mathrm{C}$ until amplification by polymerase chain reaction (PCR) method.

Samples were subjected to PCR amplification to detect the polymorphism of the eNOS gene $(T 786 C)$. The final volume of the reaction was $25 \mu \mathrm{L}$ according to the protocol proposed by Frare et al. (2013). All analyses were performed in duplicate. The resultant fragments were subjected to $1.5 \%$ agarose gel electrophoresis in 1x EDTA Tris-borate solution in an electric field of $10 \mathrm{~V} / \mathrm{cm}$. The gels were stained with ethidium bromide $(5 \mu \mathrm{g} / \mathrm{mL})$ and then visualized on the Bio-Rad Photo Documentation (Bio-Rad, Hercules, CA, USA).

For genotyping of the eNOS (T786C) gene, we performed ARMS-PCR (amplification refractory mutation system), which is referred to as the allele-specific oligonucleotide of PCR and is a technique originally designated by Newton et al. (1989) for the detection of known sequence polymorphisms. According to this technique, two primer pairs in a single-PCR tube can simultaneously amplify both mutant and normal alleles as well as allow the amplification of an internal DNA control (Wang et al., 2014).

The results of the eNOS (T786C) gene polymorphism were organized into Excel spreadsheets, composing a database. We performed the statistical analysis based on the G-test and the chi-square $\left(\chi^{2}\right)$ test to analyze the relationship between polymorphism and atherosclerotic disease. The value of $\mathrm{P}<0.05$ was considered statistically significant. The statistical tests were carried out using BioEstat ${ }^{\circledR} 5.0$ (Ayres et al., 2007).

Genetics and Molecular Research 16 (3): gmr16039708 


\section{RESULTS}

The genotype frequencies found in the eNOS (T786C) polymorphism in the case group were $10.15 \%$ (20/197) for the homozygous TT genotype, 59.39\% (117/197) for the heterozygous TC genotype, and $30.46 \%(60 / 197)$ for CC. In the control group, the genotype frequencies were $5.00 \%(5 / 100) \mathrm{TT}, 64.00 \%(64 / 100) \mathrm{TC}$, and $31.00 \%(31 / 100) \mathrm{CC}$. There was a greater prevalence of the TC allele in both case and control groups. There was no statistical difference between the case and control groups regarding the genotypic distribution $(\mathrm{P}=0.3120)$ (Table 1).

Table 1. Genotypic frequencies of the eNOS gene polymorphism in the case and control groups.

\begin{tabular}{l|c|c|c|c|c|c|c|c|c|}
\hline & \multicolumn{2}{|c|}{ TT (N) } & \multicolumn{2}{c|}{ TC (N \%) } & \multicolumn{2}{c|}{ CC (N) } & \multicolumn{2}{c|}{ Total (N \%) } & P* \\
\hline Case & 20 & 10.15 & 117 & 59.39 & 60 & 30.46 & 197 & 100.00 & \multirow{2}{*}{0.3120} \\
\hline Control & 5 & 5.00 & 64 & 64.00 & 31 & 31.00 & 100 & 100.00 & \\
\hline
\end{tabular}

*Chi-square test.

When the TC and TT genotypes were analyzed simultaneously, a frequency of $30.46 \%$ (60/197) was found for the CC genotype and 69.54\% (137/197) for the TC/TT in the case group. In the control group, the frequencies were $31.00 \%(31 / 100) \mathrm{CC}$ and $69.00 \%(69 / 100)$ TC/TT. There was no significant difference $(\mathrm{P}=0.9236)$ (Table 2$)$.

Table 2. Frequencies of the CC and TC/TT genotypes of the eNOS gene polymorphism.

\begin{tabular}{l|c|c|c|c|c|c|c}
\hline & \multicolumn{2}{|c|}{$\mathrm{CC}(\mathrm{N} \%)$} & \multicolumn{2}{|c|}{ TC/TT (N \%) } & \multicolumn{2}{c}{ Total (N \%) } & P* \\
\hline Case & 60 & 30.46 & 137 & 69.54 & 197 & 100.00 & 0.9236 \\
\hline Control & 31 & 31.00 & 69 & 69.00 & 100 & 100.00 & \\
\hline
\end{tabular}

*Chi-square test.

For the male patients in the case group, 7.86\% (7/89) presented the TT genotype, $58.43 \%(52 / 89)$ the TC genotype, and $33.71 \%(30 / 89)$ the CC genotype. In the control group, $3.78 \%(2 / 53)$ presented the TT genotype, $67.92 \%(36 / 53)$ the TC genotype, and $28.30 \%$ $(15 / 53)$ the CC genotype. The difference between the genotypes of the eNOS gene (T786C) of both groups was not statistically significant $(\mathrm{P}=0.4196)$ (Table 3$)$.

For the female patients in the case group, the frequency of TT, TC, and CC genotypes were $12.04 \%(13 / 108), 60.18 \%(65 / 108)$, and $27.78 \%$ (30/108), respectively. Among the female patients in the control group, 6.38\% (3/47) had the TT genotype, 59.58\% (28/47) had the TC genotype, and $34.04 \%(16 / 47)$ had the CC genotype. This difference was not statistically significant $(\mathrm{P}=0.4642)$ (Table 3$)$.

About the distribution of the gene polymorphism regarding the gender of the patients, in the control group of both genders, the presence of the wild-type homozygous (TT) genotype was lower, being $3.78 \%$ in men and $6.38 \%$ in women.

Regarding the smoking habit, 94 patients $(32.30 \%)$ declared to be smokers, 145 patients $(49.83 \%)$ were non-smokers, and 52 patients $(17.87 \%)$ declared to be ex-smokers, totalizing 291 patients. The inconsistency in the total number or patients is because a patient in the case group (CC) did not state whether he smokes or not; 2 patients in the case group with the TC genotype and 1 with the CC genotype declared to be ex-smokers but did not state how long they had stopped smoking, and 2 patients in the control group (TC and CC) declared themselves to be ex-smokers but did not say how long they had stopped smoking.

Genetics and Molecular Research 16 (3): gmr16039708 
Table 3. Distribution of the eNOS (T786C) gene polymorphism concerning gender in the case and control groups.

\begin{tabular}{|c|c|c|c|c|c|c|c|c|}
\hline \multirow{2}{*}{$\begin{array}{l}\text { Gender } \\
\text { Male }\end{array}$} & \multicolumn{2}{|c|}{ TT (N \%) } & \multicolumn{2}{|c|}{$\mathrm{TC}(\mathrm{N} \%)$} & \multicolumn{2}{|c|}{$\mathrm{CC}(\mathrm{N} \%)$} & Total & P* \\
\hline & & & & & & & & \\
\hline Case & 7 & 7.86 & \multirow[t]{2}{*}{52} & \multirow{2}{*}{58.43} & 30 & 33.71 & 89 & \multirow[t]{2}{*}{0.4196} \\
\hline Control & 2 & 3.78 & & & 15 & 28.30 & 53 & \\
\hline \multirow{2}{*}{\multicolumn{9}{|c|}{ Female }} \\
\hline & & 12.04 & 65 & 60.18 & 30 & 27.78 & 108 & \multirow[t]{2}{*}{0.4642} \\
\hline Control & 3 & $\begin{array}{l}6.38 \\
\end{array}$ & 28 & 59.58 & 16 & 34.04 & 47 & \\
\hline
\end{tabular}

*G-test.

Analyzing the eNOS (T786C) polymorphism of the case group, in the individuals who stated themselves as smokers, $11.59 \%(8 / 69)$ of patients had the TT genotype, 59.42\% (41/69) the TC genotype, and $28.99 \%(20 / 69)$ had CC. From the 83 atherosclerotic patients who stated to be non-smokers, $12.05 \%(10 / 83)$ had the TT genotype, $62.65 \%(52 / 83)$ had the TC genotype, and $25.30 \%(21 / 83)$ had the CC genotype. Among ex-smokers patients, that is, those who stopped smoking in the period of 15 years or more, we observed that the frequency of the TT genotype was $4.88 \%(2 / 41)$, TC genotype was $53.66 \%(22 / 41)$, and CC was $41.46 \%$ (17/41). This difference was not statistically significant $(\mathrm{P}=0.3487)$ (Table 4).

For the control group, $64.00 \%(16 / 25)$ of patients with a smoking habit presented the TC genotype and $36.00 \%(9 / 25)$, the CC genotype. No individual with the TT genotype declared to be a smoker. Regarding the patients who never smoked, 8.06\% (5/62) presented the TT genotype, $64.52 \%(40 / 62)$ the TC genotype, and $27.42 \%(17 / 62)$ the CC genotype. Among ex-smokers, the TC genotype frequency was $63.64 \%$ (7/11), and the CC genotype frequency was $36.36 \%(4 / 11)$. No individual with the TT genotype was ex-smoker. There was no statistically significant difference $(\mathrm{P}=0.2742)$ (Table 4$)$.

\begin{tabular}{|c|c|c|c|c|c|c|c|c|}
\hline Groups & \multicolumn{2}{|c|}{ TT (N \%) } & \multicolumn{2}{|c|}{ TC (N \%) } & \multicolumn{2}{|c|}{$\mathrm{CC}(\mathrm{N} \%)$} & \multirow[t]{2}{*}{ Total } & \multirow[t]{2}{*}{$\mathrm{P}^{*}$} \\
\hline \multicolumn{7}{|l|}{ Case } & & \\
\hline Smokers & 8 & 11.59 & 41 & 59.42 & 20 & 28.99 & 69 & \multirow{3}{*}{0.3487} \\
\hline Non-smokers & 10 & 12.05 & 52 & 62.65 & 21 & 25.30 & 83 & \\
\hline Ex-smokers & 2 & 4.88 & 22 & 53.66 & 17 & 41.46 & 41 & \\
\hline \multicolumn{9}{|l|}{ Control } \\
\hline Smokers & 0 & 0.00 & 16 & 64.00 & 9 & 36.00 & 25 & \multirow{3}{*}{0.2742} \\
\hline Non-smokers & 5 & 8.06 & 40 & 64.52 & 17 & 27.42 & 62 & \\
\hline Ex-smokers & 0 & 0.00 & 7 & 63.64 & 4 & 36.36 & 11 & \\
\hline
\end{tabular}

*G-test.

\section{DISCUSSION}

In the present study, we found a 2.3 -fold higher prevalence of TC/TT genotypes regarding the wild genotype (CC), both for the case and control groups. This result is similar to that of Piccoli et al. (2012), where they analyzed a South-Brazilian population and found a greater prevalence of the TC genotype in patients with acute coronary syndrome (ACS) and controls. Ragia et al. (2010) found that the TC genotype (55.2\% in the case group and $54.8 \%$ in control) had a higher prevalence concerning the other genotypes and they also did not find a statistically significant difference for patients who underwent myocardial revascularization surgery. A study conducted by Ghilardi et al. (2002) in Italian patients found that the genotypic distribution in the controls was 54 TT (41\%), 61 CT (46\%), and 18 CC (13\%), corroborating the studies in the present research. 
However, the study conducted by the Florence Nightingale Hospital Group (Istanbul, Turkey) on the $T-786 C$ polymorphism of the eNOS gene found that the CC genotype frequency was the most prevalent in the ACS group compared to the CAD and control groups. TT was the genotype most frequently observed in both patients with CAD (Ciftçi et al., 2008). Similarly, Dosenko et al. (2005) studying a group of patients with ACS in the Ukrainian population, found the C polymorphism of the 5'-flanking region of the eNOS gene 2.7-fold more frequently in patients with ACS than in controls. The authors suggested that this allelic polymorphism may be considered as one of the genetic risk factors for the development of ACS. Similarly, Gluba et al. (2009) found that in the young Polish population, the $T 786 C$ polymorphism does not increase the risk of myocardial infarction. Jaramillo et al. (2010), studying the $T 786 \mathrm{C}$ polymorphism in Chilean patients with a diagnosis of CAD found a higher frequency of the TT genotype and the distribution of that genotype was not significantly different between the individuals with CAD and control.

We found a higher prevalence of the TC genotype in the polymorphism of the eNOS gene in both genders. Agema et al. (2004) conducted a study on male patients diagnosed with CAD that corroborates our results. A higher prevalence of the TC genotype was observed both in the case and control groups, but the result was not statistically significant. Alp et al. (2009), in Turkey, reported a higher prevalence of the TT genotype in male patients with CAD $(50.6 \%)$ contradicting the present study.

According to our results on the smoking habit, a higher prevalence of the TC genotype was found, but the results were not statistically significant. Nasreen et al. (2002) evaluated genotypic frequencies in patients with a smoking habit and did not find significant differences between the groups. It is well known that smoking induces oxidative stress, which is a potent suppressor of eNOS activity (Ota et al., 1997), and alternatively, such oxidative stress may promote the degradation of NO (Kitiyakara and Wilcox, 1998). Nakayama et al. (1999) showed that the risk of coronary spasm in patients with C-786 allele was higher in smokers than in non-smokers.

Agema et al. (2004) analyzed patients with a history of myocardial infarction and the relation with smoking. Smokers and non-smokers showed a higher prevalence of the TT genotype. Alp et al. (2009) also found a higher prevalence of the TT genotype (54.8\%) in patients who have the habit of smoking; non-smoking patients presented the TC + CC genotype with higher prevalence. These results contradict the present study.

Thus, it is likely that in a condition with increased oxidative stress, such as arterial hypertension, the genetic predisposition to generate less NO may become apparent and, in the long run, may be detrimental, resulting in a susceptibility to atherogenesis. Rossi et al. (2003) found that the combination of at least one major cardiovascular risk factor increased the risk associated with the $\mathrm{C}$ allele.

In conclusion, the presence of multiple risk factors increased the deleterious effects of the $\mathrm{C}$ allele. Moreover, most conditions involving oxidative stress, such as aging, smoking, hypercholesterolemia, male gender (lack of estrogen), and overweight or obesity lead to a genetic predisposition that generates less $\mathrm{NO}$, which is associated with the $\mathrm{C}$ allele, contribute to decreasing NO bioavailability, and finally, the onset of coronary atherogenesis.

\section{Conflicts of interest}

The authors declare no conflict of interest.

Genetics and Molecular Research 16 (3): gmr16039708 


\section{ACKNOWLEDGMENTS}

We thank Pontificial Catholic University of Goiás, Goiânia, Brazil (Replicon / Prope / MGene / FAPEG / CNPq) for the contribution and support to make this research possible.

\section{REFERENCES}

Agema WRP, de Maat MP, Zwinderman AH, Kastelein JJ, et al. (2004). An integrated evaluation of endothelial constitutive nitric oxide synthase polymorphisms and coronary artery disease in men. Clin. Sci. 107: 255-261. https://doi. org $/ 10.1042 / \mathrm{CS} 20030360$

Alp E, Menevse S, Tulmac M, Kan D, et al. (2009). Lack of association between matrix metalloproteinase-9 and endothelial nitric oxide synthase gene polymorphisms and coronary artery disease in Turkish population. DNA Cell Biol. 28: 343350. https://doi.org/10.1089/dna.2009.0866

Ayres M, Ayres Júnior M, Ayres DL and Santos AA (2007). BioEstat 5.0: aplicações estatísticas nas áreas das ciências biológicas e médicas. MCT; IDSM; CNPq, Belém.

Balagopal PB, de Ferranti SD, Cook S, Daniels SR, et al.; American Heart Association Committee on Atherosclerosis Hypertension and Obesity in Youth of the Council on Cardiovascular Disease in the Young; Council on Nutrition, Physical Activity and Metabolism; Council on Epidemiology and Prevention (2011). Nontraditional risk factors and biomarkers for cardiovascular disease: mechanistic, research, and clinical considerations for youth: a scientific statement from the American Heart Association. Circulation 123: 2749-2769. https://doi.org/10.1161/CIR.0b013e31821c7c64

Charakida M, Masi S, Lüscher TF, Kastelein JJ, et al. (2010). Assessment of atherosclerosis: the role of flow-mediated dilatation. Eur. Heart J. 31: 2854-2861. https://doi.org/10.1093/eurheartj/ehq340

Ciftçi C, Melil S, Çebi Y, Ersöz M, et al. (2008). Association of endothelial nitric oxide synthase promoter region (T-786C) gene polymorphism with acute coronary syndrome and coronary heart disease. Lipids Health Dis. 7: 5. https://doi. org/10.1186/1476-511X-7-5

Davignon J and Ganz P (2004). Role of endothelial dysfunction in atherosclerosis. Circulation 109 (Suppl 1): III27-III32. https://doi.org/10.1161/01.CIR.0000131515.03336.f8

Dosenko VIe, Zahoriĭ VIu, Lutaĭ IaM, Parkhomenko OM, et al. (2005). Allelic polymorphism of endothelial NO-synthase (T(-786)-->C) promoter gene as risk factor of acute coronary syndrome. Fiziol. Zh. 51: 72-76.

Félétou M and Vanhoutte PM (2006). Endothelial dysfunction: a multifaceted disorder (The Wiggers Award Lecture). Am. J. Physiol. Heart Circ. Physiol. 291: H985-H1002. https://doi.org/10.1152/ajpheart.00292.2006

Frare AB, Barbosa AM, Costa IR, Souza SR, et al. (2013). GSTM1 and GSTT1 polymorphisms in endometriosis in women from Goiás, Brazil. Genet. Mol. Res. 12: 2764-2770. https://doi.org/10.4238/2013.August.2.1

Ghilardi G, Biondi ML, DeMonti M, Bernini M, et al. (2002). Independent risk factor for moderate to severe internal carotid artery stenosis: T786C mutation of the endothelial nitric oxide synthase gene. Clin. Chem. 48: 989-993.

Giannotti G and Landmesser U (2007). Endothelial dysfunction as an early sign of atherosclerosis. Herz 32: 568-572. https://doi.org/10.1007/s00059-007-3073-1

Gluba A, Banach M, Rysz J, Piotrowski G, et al. (2009). Is polymorphism within eNOS gene associated with the late onset of myocardial infarction? A pilot study. Angiology 60: 588-595. https://doi.org/10.1177/0003319709335031

Gomma AH, Elrayess MA, Knight CJ, Hawe E, et al. (2002). The endothelial nitric oxide synthase (Glu298Asp and $-786 \mathrm{~T}>$ C) gene polymorphisms are associated with coronary in-stent restenosis. Eur. Heart J. 23: 1955-1962. https:// doi.org/10.1053/euhj.2002.3400

Gorenne I, Kavurma M, Scott S and Bennett M (2006). Vascular smooth muscle cell senescence in atherosclerosis. Cardiovasc. Res. 72: 9-17. https://doi.org/10.1016/j.cardiores.2006.06.004

Jaramillo PC, Lanas C, Lanas F and Salazar LA (2010). Polymorphisms of the NOS3 gene in Southern Chilean subjects with coronary artery disease and controls. Clin. Chim. Acta 411: 258-262. https://doi.org/10.1016/j.cca.2009.11.018

Kitiyakara C and Wilcox CS (1998). Antioxidants for hypertension. Curr. Opin. Nephrol. Hypertens. 7: 531-538. https:// doi.org/10.1097/00041552-199809000-00008

Konsola T, Siasos G, Antonopoulos AS, Kollia C, et al. (2016). The impact of T786C and G894T polymorphisms of eNOS on vascular endothelial growth factor serum levels in type 2 diabetes patients. Int. J. Cardiol. 222: 155-156 https:// doi.org/10.1016/j.ijcard.2016.07.238.

Landmesser U, Hornig B and Drexler H (2004). Endothelial function: a critical determinant in atherosclerosis? Circulation 109 (Suppl 1): II27-II33. https://doi.org/10.1161/01.CIR.0000129501.88485.1f

Li H and Förstermann U (2009). Prevention of atherosclerosis by interference with the vascular nitric oxide system. Curr. Pharm. Des. 15: 3133-3145. https://doi.org/10.2174/138161209789058002

Genetics and Molecular Research 16 (3): gmr16039708 
Li H, Wallerath T, Münzel T and Förstermann U (2002). Regulation of endothelial-type NO synthase expression in pathophysiology and in response to drugs. Nitric Oxide 7: 149-164. https://doi.org/10.1016/S1089-8603(02)00111-8

Libby P (2013). Mechanisms of acute coronary syndromes and their implications for therapy. N. Engl. J. Med. 368: 20042013. https://doi.org/10.1056/NEJMra1216063

Lüscher TF and Noll G (1999). Is it all in the genes...? Nitric oxide synthase and coronary vasospasm. Circulation 99: 2855-2857. https://doi.org/10.1161/01.CIR.99.22.2855

McNamara DM, Holubkov R, Postava L, Ramani R, et al. (2003). Effect of the Asp298 variant of endothelial nitric oxide synthase on survival for patients with congestive heart failure. Circulation 107: 1598-1602. https://doi. org/10.1161/01.CIR.0000060540.93836.AA

Miyamoto Y, Saito Y, Nakayama M, Shimasaki Y, et al. (2000). Replication protein A1 reduces transcription of the endothelial nitric oxide synthase gene containing a -786T-->C mutation associated with coronary spastic angina. Hum. Mol. Genet. 9: 2629-2637. https://doi.org/10.1093/hmg/9.18.2629

Monti LD, Barlassina C, Citterio L, Galluccio E, et al. (2003). Endothelial nitric oxide synthase polymorphisms are associated with type 2 diabetes and the insulin resistance syndrome. Diabetes 52: 1270-1275. https://doi.org/10.2337/ diabetes.52.5.1270

Nakayama M, Yasue H, Yoshimura M, Shimasaki Y, et al. (1999). T-786-->C mutation in the 5'-flanking region of the endothelial nitric oxide synthase gene is associated with coronary spasm. Circulation 99: 2864-2870. https://doi. org/10.1161/01.CIR.99.22.2864

Nakayama M, Yasue H, Yoshimura M, Shimasaki Y, et al. (2000). T(-786)--> C mutation in the $5^{\prime}$-flanking region of the endothelial nitric oxide synthase gene is associated with myocardial infarction, especially without coronary organic stenosis. Am. J. Cardiol. 86: 628-634. https://doi.org/10.1016/S0002-9149(00)01041-9

Nanni L, Romualdi C, Maseri A and Lanfranchi G (2006). Differential gene expression profiling in genetic and multifactorial cardiovascular diseases. J. Mol. Cell. Cardiol. 41: 934-948. https://doi.org/10.1016/j.yimcc.2006.08.009

Nasreen S, Nabika T, Shibata H, Moriyama H, et al. (2002). T-786C polymorphism in endothelial NO synthase gene affects cerebral circulation in smokers: possible gene-environmental interaction. Arterioscler. Thromb. Vasc. Biol. 22: 605-610. https://doi.org/10.1161/01.ATV.0000013286.60021.FE

Newton CR, Graham A, Heptinstall LE, Powell SJ, et al. (1989). Analysis of any point mutation in DNA. The amplification refractory mutation system (ARMS). Nucleic Acids Res. 17: 2503-2516. https://doi.org/10.1093/nar/17.7.2503

Ota Y, Kugiyama K, Sugiyama S, Ohgushi M, et al. (1997). Impairment of endothelium-dependent relaxation of rabbit aortas by cigarette smoke extract--role of free radicals and attenuation by captopril. Atherosclerosis 131: 195-202. https://doi.org/10.1016/S0021-9150(97)06106-6

Paradossi U, Ciofini E, Clerico A, Botto N, et al. (2004). Endothelial function and carotid intima-media thickness in young healthy subjects among endothelial nitric oxide synthase Glu298-->Asp and T-786-->C polymorphisms. Stroke 35: 1305-1309. https://doi.org/10.1161/01.STR.0000126482.86708.37

Piccoli JCE, Manfredini V, Hamester FI, Bandinelli JB, et al. (2012). Interaction between endothelial nitric oxide synthase gene polymorphisms $(-786 \mathrm{~T}>\mathrm{C}, 894 \mathrm{G}>\mathrm{T}$ and intron $4 \mathrm{a} / \mathrm{b})$ and cardiovascular risk factors in acute coronary syndromes. Arch. Med. Res. 43: 205-211. https://doi.org/10.1016/j.arcmed.2012.03.011

Puddu P, Puddu GM, Bastagli L, Massarelli G, et al. (1995). Coronary and cerebrovascular atherosclerosis: two aspects of the same disease or two different pathologies? Arch. Gerontol. Geriatr. 20: 15-22. https://doi.org/10.1016/01674943(94)00600-C

Ragia G, Nikolaidis E, Tavridou A, Arvanitidis KI, et al. (2010). Endothelial nitric oxide synthase gene polymorphisms $-786 \mathrm{~T}>\mathrm{C}$ and $894 \mathrm{G}>\mathrm{T}$ in coronary artery bypass graft surgery patients. Hum. Genomics $4: 375-383$. https://doi. org/10.1186/1479-7364-4-6-375

Robert RS (2005). HDL-C and the diabetic patient: target for therapeutic intervention? Diabetes Res. Clin. Pract. 68 (Suppl 2): S36-S42. https://doi.org/10.1016/j.diabres.2005.03.013

Rossi GP, Cesari M, Zanchetta M, Colonna S, et al. (2003). The T-786C endothelial nitric oxide synthase genotype is a novel risk factor for coronary artery disease in Caucasian patients of the GENICA study. J. Am. Coll. Cardiol. 41: 930-937. https://doi.org/10.1016/S0735-1097(02)03012-7

Wang YZ, Zhu Z, Zhang HY, Zhu MZ, et al. (2014). Detection of hepatitis B virus A1762T/G1764A mutant by amplification refractory mutation system. Braz. J. Infect. Dis. 18: 261-265. https://doi.org/10.1016/j.bjid.2013.09.005

Yoshimura T, Hisatomi A, Kajihara S, Yasutake T, et al. (2003). The relationship between insulin resistance and polymorphisms of the endothelial nitric oxide synthase gene in patients with coronary artery disease. $J$. Atheroscler. Thromb. 10: 43-47. https://doi.org/10.5551/jat.10.43

Zeng WP, Zhang R, Li R, Luo JF, et al. (2017). Association of the Endothelial Nitric Oxide Synthase Gene T786C Polymorphism with In-Stent Restenosis in Chinese Han Patients with Coronary Artery Disease Treated with DrugEluting Stent. PLoS One 12: e0170964. https://doi.org/10.1371/journal.pone.0170964

Genetics and Molecular Research 16 (3): gmr16039708 